\title{
Selenoneine, a Novel Selenium-Containing Compound, Mediates Detoxification Mechanisms against Methylmercury Accumulation and Toxicity in Zebrafish Embryo
}

\author{
Michiaki Yamashita • Yumiko Yamashita • Tamami Suzuki • \\ Yoko Kani • Nanami Mizusawa • Shintaro Imamura • Kenji Takemoto • \\ Tatsuro Hara • Md. Anwar Hossain • Takeshi Yabu • Ken Touhata
}

Received: 6 October 2012 /Accepted: 19 March 2013 /Published online: 25 May 2013

(C) The Author(s) 2013. This article is published with open access at Springerlink.com

\begin{abstract}
The selenium (Se)-containing antioxidant selenoneine (2-selenyl- $N_{\alpha}, N_{\alpha}, N_{\alpha}$-trimethyl-L-histidine) has recently been discovered to be the predominant form of organic Se in tuna blood. Although dietary intake of fish Se has been suggested to reduce methylmercury $(\mathrm{MeHg})$ toxicity, the molecular mechanism of $\mathrm{MeHg}$ detoxification by Se has not yet been determined. Here, we report evidence that selenoneine accelerates the excretion and demethylation of $\mathrm{MeHg}$, mediated by a selenoneine-specific transporter, organic cations/carnitine transporter-1 (OCTN1). Selenoneine was incorporated into human embryonic kidney HEK293 cells transiently overexpressing OCTN1 and zebrafish blood cells by OCTN1. The $K_{\mathrm{m}}$ for selenoneine uptake was $13.0 \mu \mathrm{M}$ in OCTN1-overexpressing HEK293 cells and $9.5 \mu \mathrm{M}$ in zebrafish blood cells, indicating high affinity of OCTN1 for selenoneine in human and zebrafish cells. When such OCTN1-expressing cells and embryos were exposed to $\mathrm{MeHg}$-cysteine (MeHgCys), MeHg accumulation was decreased and the excretion and demethylation of $\mathrm{MeHg}$ were enhanced by selenoneine. In addition, exosomal secretion
\end{abstract}

Electronic supplementary material The online version of this article (doi:10.1007/s10126-013-9508-1) contains supplementary material, which is available to authorized users.

M. Yamashita $(\bowtie) \cdot$ Y. Yamashita $\cdot$ T. Suzuki $\cdot$ Y. Kani $\cdot$

N. Mizusawa $\cdot$ S. Imamura $\cdot$ K. Takemoto $\cdot$ T. Hara $\cdot$

M. A. Hossain $\cdot$ T. Yabu $\cdot$ K. Touhata

National Research Institute of Fisheries Science, 2-12-4 Fukuura,

Yokohama, Kanagawa 236-8648, Japan

e-mail: mic@affrc.go.jp

Present Address:

T. Yabu

Nihon University, 1866 Kameino,

Fujisawa, Kanagawa 252-0880, Japan vesicles were detected in the culture water of embryos that had been microinjected with $\mathrm{MeHgCys,} \mathrm{suggesting} \mathrm{that}$ these may be responsible for $\mathrm{MeHg}$ excretion and demethylation. In contrast, OCTN1-deficient embryos accumulated $\mathrm{MeHg}$, and $\mathrm{MeHg}$ excretion and demethylation were decreased. Furthermore, Hg accumulation was decreased in OCTN1-overexpressing HEK293 cells, but not in mock vector-transfected cells, indicating that selenoneine and OCTN1 can regulate $\mathrm{MeHg}$ detoxification in human cells. Thus, the selenoneine-mediated OCTN1 system regulates secretory lysosomal vesicle formation and $\mathrm{MeHg}$ demethylation.

Keywords Methylmercury · Mercury · OCTN1 - Selenium · Demethylation · Detoxification

$\begin{array}{ll}\begin{array}{l}\text { Abbreviations } \\ \text { ABC }\end{array} & \text { ATP-binding cassette } \\ \text { baf } & \text { Bafilomycin A1 } \\ \text { ESCRT } & \begin{array}{l}\text { Endosomal sorting complex required for } \\ \text { transport }\end{array} \\ \mathrm{Hg} & \text { Mercury } \\ \mathrm{HgSe} & \text { Mercury selenide } \\ \mathrm{HEK} 293 & \text { Human embryonic kidney 293 cell line } \\ \text { hpf } & \text { Hours post-fertilization } \\ \mathrm{HPF} & \text { Hydroxyphenyl fluorescein } \\ \text { LC-ICP-MS } & \text { Liquid chromatography-inductively coupled } \\ & \text { plasma mass spectrometry } \\ \text { MeHg } & \text { Methylmercury } \\ \text { MeHgCys } & \text { MeHg-cysteine } \\ \text { MO } & \text { Morpholino oligonucleotide } \\ \text { OCTN1 } & \text { Organic cations/carnitine transporter-1 } \\ \text { phOCTN1 } & \text { Human OCTN1 expression vector }\end{array}$


ROS Reactive oxygen species

Se Selenium

\section{Introduction}

Dietary intake of selenium (Se), which is found in fish, can reduce methylmercury (MeHg) toxicity (Friedman et al. 1978; Ganther and Sunde 1974; Ganther et al. 1972; Ohi et al. 1980; Raymond and Ralston 2004; Raymond et al. 2012). Ganther et al. (1972) demonstrated that intake of canned tuna meat containing slightly elevated $\mathrm{MeHg}$ levels reduced the toxicity to Japanese quail and suggested the protective role of Se. Friedman et al. (1978) showed a protective effect of freezedried swordfish meat against $\mathrm{MeHg}$ toxicity in rats, and Ohi et al. (1980) suggested that an unknown organic Se compound in fish meat could reduce $\mathrm{MeHg}$ neurotoxicity.

Recently, a novel Se compound, selenoneine, was identified in the blood of bluefin tuna and distributed in fish muscles (Yamashita and Yamashita 2010; Yamashita et al. 2010; 2011). The generation of reactive oxygen species (ROS) has been linked to MeHg-induced toxicity both in vivo and in vitro (Petroni et al. 2012; Yin et al. 2007; Usuki et al. 2011), and selenoneine has strong radical scavenging properties (Yamashita and Yamashita 2010; Yamashita et al. 2010, 2011). Thus, selenoneine is proposed to be a biologically and nutritionally active chemical with the ability to detoxify $\mathrm{MeHg}$ in animal cells and tissues.

With one Se atom in its imidazole ring, selenoneine is a Se analog of ergothioneine (Yamashita and Yamashita 2010). The organic cations/carnitine transporter, OCTN1 [solute carrier family 22, member 4; SLC22A4], transports ergothioneine and carnitine (Gründemann et al. 2005; Tamai et al. 1999) and therefore may also be involved in the uptake of selenoneine and its detoxification of MeHg. OCTN1 is ubiquitously distributed in mammalian cells and tissues, with erythrocytes having the highest OCTN1 mRNA levels (Gründemann et al. 2005; Tamai et al. 1999). Human embryonic kidney 293 (HEK293) cells transfected with an OCTN1 expression vector showed specific uptake of ergothioneine (Gründemann et al. 2005). The slc22a4 transporter gene has also been identified and expressed in zebrafish blood cells and other cell types, as expected given its role in heme metabolism (Nilsson et al. 2009; Weber et al. 2005).

To identify the MeHg excretion pathway mediated by the selenium redox function, we focused on the ceramidemediated exosome secretion pathway. It has been shown recently that the formation and release of exosomes (small membrane-bound vesicles) by the endosomal sorting complex required for transport (ESCRT) machinery is triggered by ceramide generation (Trajkovic et al. 2008). Ceramide is produced by the hydrolytic action of sphingomyelinase (SMase) on substrate sphingomyelin in response to various agonists or stresses such as irradiation, heat shock, and oxidative stress (Hannun 1996; Mathias et al. 1993; Okazaki et al. 1989; Verheij et al. 1996; Yabu et al. 2008). The sphingomyelin pathway may be linked to stressinducible apoptosis and detoxification under oxidative stress conditions produced by $\mathrm{MeHg}$ exposure.

Inorganic mercury $(\mathrm{Hg})$ is distributed in marlin meat and in the livers and kidneys of fish and laboratory animals chronically exposed to MeHg (Clarkson 1972; Friberg and Mottet 1989; Itano et al. 1985; $\mathrm{Ng}$ et al. 2001; Nigro and Leonzio 1996; Palmisano et al. 1995; Skerfving 1978). Although demethylation of $\mathrm{MeHg}$ is thought to be an important route of detoxification, the underlying molecular mechanism is poorly understood. Therefore, the effects of chronic exposure to low $\mathrm{MeHg}$ levels should be characterized in animal models.

Bioaccumulation and detoxification of heavy metals in aquatic and marine organisms are important research topics in the field of marine biotechnology (Auslander et al. 2008; Cordeiro et al. 2012; De et al. 2008; Ma et al. 2012). The zebrafish is a useful model organism for studying embryonic development and is increasingly being used in vertebrate toxicology studies (Gonzalez et al. 2005; Korbas et al. 2008; Kusik et al. 2008; Samson et al. 2001; Weber et al. 2008). Previously, embryonic and larval zebrafish have been used to study the toxic effects of $\mathrm{MeHg}$ exposure on the entire body (Samson et al. 2001; Weber et al. 2008) and at the molecular level (Gonzalez et al. 2005; Korbas et al. 2008). Because the nucleotide sequence and expression of the zebrafish OCTN1 gene homolog has been characterized (Nilsson et al. 2009; Weber et al. 2005), OCTN1-deficient embryos can be generated by microinjection of an antisense morpholino oligo (MO) and used for the study of $\mathrm{MeHg}$ toxicity.

In the present study, we investigated the involvement of selenoneine and OCTN1 in MeHg detoxification using the zebrafish embryo model. The specific incorporation of selenoneine through OCTN1 was characterized in zebrafish embryos. In addition, the incorporation of selenoneine through the human homolog of OCTN1 was characterized in HEK293 cells. Morphological defects and apoptosis induced by $\mathrm{MeHg}$ were decreased by selenoneine exposure, and selenoneine reduced $\mathrm{MeHg}$ accumulation and induced demethylation of $\mathrm{MeHg}$ in embryos and HEK293 cells. Additionally, OCTN1-deficient zebrafish embryos showed excess accumulation of $\mathrm{MeHg}$ and increased sensitivity to $\mathrm{MeHg}$ exposure.

\section{Materials and Methods}

\section{Materials}

The dimeric oxidized form of selenoneine was purified from the blood of bluefin tuna according to methods described previously (Yamashita and Yamashita 2010). Ergothioneine 
and glutathione peroxidase 1 was purchased from SigmaAldrich Japan (Tokyo, Japan). Selenoneine and ergothioneine were dissolved in ultrapure water. $\mathrm{MeHg}$-cysteine (MeHgCys) solution was prepared from $\mathrm{MeHg}$ chloride (STREM Chemicals, Newburyport, MA, USA) and L-cysteine hydrochloride (Wako Pure Chemical Industries, Osaka, Japan) according to the method described in the Mercury Analysis Manual (Ministry of the Environment, Japan 2004).

\section{Fish Maintenance}

Zebrafish (Danio rerio) were maintained at $28.5^{\circ} \mathrm{C}$ on a $14 \mathrm{~h}$ light/10 h dark cycle, as described previously (Westerfield 1995). Fertilized one-cell stage embryos were collected from wild-type zebrafish and microinjected with linearized plasmid DNA at $0.5 \mathrm{ng}$ per embryo or antisense MO at $10 \mathrm{ng}$ per embryo using methods described previously (Yamashita et al. 2008). Microinjected zebrafish embryos (30 individuals) were cultured in Hank's solution (Yamashita et al. 2008) in a 6-cm dish at $28.5^{\circ} \mathrm{C}$. To inhibit the lysosomal function, a vacuolartype $\mathrm{H}^{+}$-ATPase inhibitor, bafilomycin A1 (baf; Wako Pure Chemical Industries), was added to the culture medium at a concentration of $5 \mathrm{nM} 12 \mathrm{~h}$ post-fertilization (hpf), according to the manufacturer's instructions. For the MeHgCys toxicity assay, zebrafish embryos were cultured in Hank's solution, and eggs containing dead or obviously poor-quality embryos were removed. The remaining embryos were used, usually within $1 \mathrm{hpf}$, for developmental toxicity assays. Selenoneine treatment of embryos in 24-well microtiter plates began at 48 hpf. Symptoms in the zebrafish were continuously observed, and dead individuals were promptly removed. The number of deaths at $48 \mathrm{hpf}$ was recorded.

\section{Cell Culture and Transfection}

HEK293 cells were obtained from the Health Science Research Resources Bank (Osaka, Japan) and cultured in RPMI-1640 (Invitrogen, Carlsbad, CA, USA) supplemented with $10 \%$ fetal calf serum at $37{ }^{\circ} \mathrm{C}$ in a humidified $5 \% \mathrm{CO}_{2}$ incubator. Linearized vector (phOCTN1) for human OCTN1 expression under the control of the human cytomegalovirus promoter (sc126568; Origene, Rockville, MD, USA) was transiently transfected into HEK293 cells using FuGene ${ }^{\circledR}$ HD Transfection Reagent (Roche Diagnotics Japan, Tokyo, Japan). The cells were cultured in a 24-well culture plate (Corning International, Tokyo, Japan) for $24 \mathrm{~h}$ after transfection, harvested by trypsinization ( $0.05 \%$ trypsin/ $0.53 \mathrm{mM}$ EDTA), washed twice with PBS, and collected by centrifugation.

\section{Antisense MO}

For knockdown experiments, two antisense MOs (antisenseMO1: CAT TTT AGC CTT CAG TTG CC and antisense-
MO2: CGT GAT GTC GTC ATA ATC CCT CAT; Gene Tools, Boston, MA, USA) specific for zebrafish OCTN1 (Nilsson et al. 2009) were microinjected into one-cell stage zebrafish embryos (10 ng per embryo). Another MO with five mispaired bases (5'-mis control MO: CAA TTA AGG CTA CAC TTG CC) and a standard control oligo (control MO: CCT CTT ACC TCA GTT ACA ATT TAT A) (Gene Tools) were used as negative controls.

\section{TUNEL Staining}

Whole-mount TUNEL staining was performed as described previously (Yamashita et al. 2008).

\section{Western Blot Analysis}

Cultured cells and embryos were homogenized with $1 / 4$ volume of $5 \times$ sample buffer $[0.2 \mathrm{M}$ Tris- $\mathrm{HCl}, \mathrm{pH} 6.8,10 \% \mathrm{SDS}$, $10 \mathrm{mM} 2$-mercaptoethanol, $20 \%$ glycerol, $0.05 \%$ bromophenol blue, and protease inhibitor cocktail (Roche Diagnostics, Tokyo, Japan)], heated at $100{ }^{\circ} \mathrm{C}$ for $1 \mathrm{~min}$, and clarified by centrifugation at $10,000 \times \mathrm{g}$ for $10 \mathrm{~min}$ at $4{ }^{\circ} \mathrm{C}$. The proteins were separated in a $10 \%$ gel by SDS-PAGE and electroblotted onto a polyvinylidene difluoride membrane (GE Healthcare Japan, Tokyo, Japan). Polyclonal antibody against human OCTN1 (1:1,000 dilution, Santa Cruz Biotechnology, Santa Cruz, CA, USA) was used as the primary antibody, with a horse radish peroxidase-conjugated secondary antibody (1:2,000 dilution, Daco Japan, Tokyo, Japan). Immunoreactive bands were detected using an ECL ${ }^{\mathrm{TM}}$ Western blotting detection kit (GE Healthcare Japan) according to the manufacturer's protocol.

\section{Selenium Concentration Measurement}

Organic Se compounds were identified by speciation analysis using a previously described method (Yamashita and Yamashita 2010; Yamashita et al. 2011). Selenoneine and other Se-containing compounds were separated by chromatography using an Ultrahydrogel 120 column $(7.8 \times 250 \mathrm{~mm}$; Nihon Waters, Tokyo, Japan) equilibrated with $100 \mathrm{mM}$ ammonium formate buffer containing $0.1 \%(w / v)$ Igepal CA-630 (Sigma-Aldrich Japan), and ${ }^{82} \mathrm{Se}$ was detected by online liquid chromatography-inductively coupled plasma mass spectrometry (LC-ICP-MS) performed using an ELAN DRC II mass spectrometer (PerkinElmer, Waltham, MA, USA). During separation, selenoneine was eluted at a retention time of $10.1 \mathrm{~min}$, and the Se concentration was determined using selenoneine as a standard. For the Se assay of embryo tissues, embryos at $72 \mathrm{hpf}$ were dissected with two pairs of fine forceps, and brains and blood cells were collected in PBS with a Pasteur pipette under a dissecting microscope. Pooled samples, each containing the tissues or blood cells of 10 embryos, 
were used for the selenium assay. The cells and tissues were homogenized in $100 \mathrm{mM}$ ammonium formate buffer containing $0.1 \%(w / v)$ Igepal CA-630 using a Polytron homogenizer (Kinematica, Luzernerstrasse, Switzerland) on ice, the cellular lysate was clarified by centrifugation at $10,000 \times \mathrm{g}$ for $10 \mathrm{~min}$, and the supernatant was used for Se determination. Total Se content in cellular extracts was analyzed by the flow injection method using LC-ICP-MS with selenoneine as a standard (Yamashita and Yamashita 2010). For the analysis of $K_{\mathrm{m}}$ values for selenoneine uptake, HEK293 cells transfected with OCTN1 and the blood cells collected from 72-hpf embryos were treated with selenoneine at concentrations from 1.6 to $32 \mu \mathrm{M}$ in the culture medium. The $K_{\mathrm{m}}$ values were calculated by nonlinear regression of the Michaelis-Menten equation using Prism ver. 5 (GraphPad Software, La Jolla, CA, USA).

\section{Hg Concentration Determination}

After chemical digestion of samples with a 1:2:1 mixture of nitric acid/perchloric acid/sulfuric acid (Yamashita et al. 2005), total $\mathrm{Hg}$ levels were determined by flameless atomic absorption spectrometry at $253.7 \mathrm{~nm}$, performed using an HG-310 mercury analyzer (Hiranuma, Tokyo, Japan) according to the manufacturer's instructions. After inorganic $\mathrm{Hg}$ and $\mathrm{MeHg}$ were extracted from tissue samples using $5 \mathrm{M} \mathrm{HCl}$ and $0.25 \mathrm{M}$ $\mathrm{NaCl}$ at $60^{\circ} \mathrm{C}$ for $10 \mathrm{~min}$ (Reyes et al. 2009), inorganic $\mathrm{Hg}$ and $\mathrm{MeHg}$ were determined by LC-ICP-MS with a reversephase $\mathrm{C} 18$ column (Inertsil ${ }^{\circledR}$ Sulfa $\mathrm{C} 18,150 \times 4.6 \mathrm{~mm}$; GL Sciences, Tokyo Japan) by isocratic elution with $50 \mathrm{mM}$ pyridine, $0.5 \%(w / v)$ L-cysteine, and $5 \%(v / v)$ methanol at $\mathrm{pH} 3$ and room temperature.

\section{ROS Assay}

Hydroxyl radical concentrations were determined by measuring the fluorescence signal of hydroxyphenyl fluorescein (HPF; Sekisui Medical, Tokyo, Japan) according to the manufacturer's instruction. Each embryo was placed in a $1.5-\mathrm{ml}$ microcentrifuge tube and homogenized in diluted HPF solution (1:1,000 in ultrapure water) using a Pellet Mixer Pestle (Treff, Degersheim, Switzerland). After centrifugation at $10,000 \times g$ for $5 \mathrm{~min}$, the fluorescence intensity of the extract was measured with a fluorescence spectrophotometer (model 850, Hitachi, Tokyo, Japan) at excitation and emission wavelengths of 490 and $515 \mathrm{~nm}$, respectively. ROS levels were defined using arbitrary units of fluorescence intensity per milligram of protein.

Protein Determination

Protein concentrations were determined with a Bio-Rad protein assay kit (Bio-Rad Laboratories, Hercules, CA, USA) using bovine serum albumin (Sigma-Aldrich) as a standard.
Ultracentrifugal Separation of Exosomes from Culture Water of Embryos

After the microinjection of MeHgCys ( $3 \mathrm{ng} \mathrm{Hg}$ ) into the yolk at $12 \mathrm{hpf}$ and the removal of the chorion using forceps, zebrafish embryos (30 individuals) were cultured in Hank's solution for $12 \mathrm{~h}$. The $\mathrm{MeHg}$ and inorganic $\mathrm{Hg}$ contents of the embryos were determined. Embryo culture water $(5 \mathrm{~mL})$ was centrifuged at $3,000 \times \mathrm{g}$ for $15 \mathrm{~min}$ at $4{ }^{\circ} \mathrm{C}$ to remove broken tissues and cells. The supernatant was layered above $20 \mathrm{mM}$ Tris- $\mathrm{HCl}$ buffer ( $\mathrm{pH}$ 7.4) containing $150 \mathrm{mM} \mathrm{NaCl}$ and $250 \mathrm{mM}$ sucrose $(10 \mathrm{~mL})$ and ultracentrifuged at $100,000 \times \mathrm{g}$ for $1 \mathrm{~h}$ at $4{ }^{\circ} \mathrm{C}$. The pellet was suspended in $0.5 \mathrm{ml}$ of $20 \mathrm{mM}$ Tris-HCl buffer ( $\mathrm{pH} 7.4$ ) containing $150 \mathrm{mM} \mathrm{NaCl}$ and $0.1 \%$ Tween-20, and used as the exosomal fraction. Cathepsin L activity was measured with Z-Phe-Arg- $\alpha$-methylcoumaryl-7amide (pH 5.6) as a substrate (Yamashita and Konagaya 1990). One unit of enzyme activity was defined as the release of $1 \mathrm{nmol}$ of aminomethylcoumarin per hour at $37^{\circ} \mathrm{C}$.

\section{Statistical Analysis}

The results are expressed as means \pm standard error. Differences among groups were analyzed using Prism ver. 5 (GraphPad Software).

\section{Results}

OCTN1 as the Selenoneine Transporter

Owing to the structural similarity between selenoneine and ergothioneine, we examined whether OCTN1, which is an ergothioneine transporter, could transport selenoneine by measuring Se incorporation in HEK293 cells transiently overexpressing OCTN1 transporter (Fig. 1). The overexpression of OCTN1 in HEK293 cells was confirmed by immunoblotting

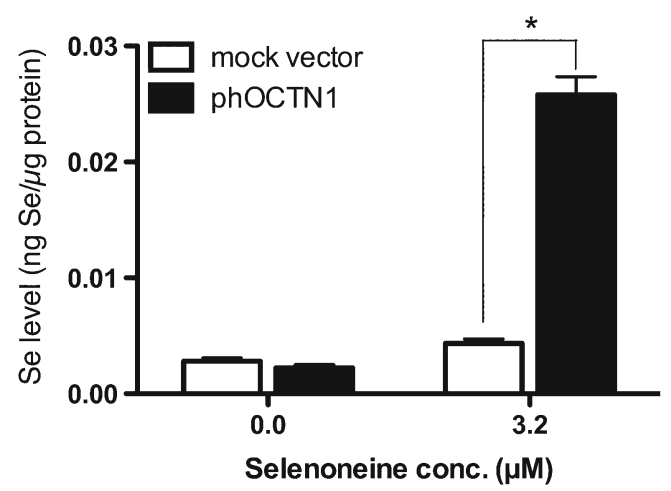

Fig. 1 Specific incorporation of selenoneine in HEK293 cells. HEK293 cells transiently transfected with mock control or phOCTN1 expression vector were assayed for the incorporation of selenium in the presence and absence of $3.2 \mu \mathrm{M}$ selenoneine 
(Fig. S1). The addition of selenoneine to the cell culture medium caused Se levels in OCTN1-transfected cells to be 5.9 times those in mock vector-transfected cells. Selenoneine was incorporated into mock vector-transfected cells at a level 1.5 times that in selenoneine-untreated cells, suggesting that OCTN1 was also expressed in the control cells (Fig. 1).

OCTN1-deficient zebrafish embryos generated by microinjection of antisense MO1 showed reduced expression of OCTN1, as demonstrated by whole-mount immunostaining (Fig. S2A) and Western blot analysis (Fig. S1). When cultured in selenoneine-containing medium, the morphant OCTN1-deficient embryos showed reduced accumulation of selenoneine compared with that in control zebrafish embryos (Fig. 2, Fig. S2B), which incorporated selenoneine within $30 \mathrm{~min}$ of its addition to the culture medium (Fig. S3A, B). Thus, OCTN1 acted as a selenoneine transporter in human cells in vitro and in zebrafish embryos in vivo.

We measured the specific uptake of selenoneine by HEK293 cells overexpressing OCTN1 and blood cells collected from a 3-day-old zebrafish embryo in medium containing 1.6-32 $\mu \mathrm{M}$ selenoneine. The $K_{\mathrm{m}}$ values for selenoneine uptake were estimated to be 13.0 and $9.5 \mu \mathrm{M}$, respectively. These were lower than those previously reported for ergothioneine uptake by OCTN1 (21 $\mu \mathrm{M}$ in OCTN1transfected HEK293 cells) (Gründemann et al. 2005; Tamai et al. 1999). Because selenoneine was found to have a higher affinity for OCTN1, it may be the most specific ligand and is incorporated into cultured cells and embryos when present at micromolar concentrations.

\section{Protective Effects of Selenoneine Against $\mathrm{MeHg}$} Accumulation and Toxicity

To evaluate the protective effect of selenoneine against $\mathrm{MeHg}$ accumulation, we established a zebrafish embryo-

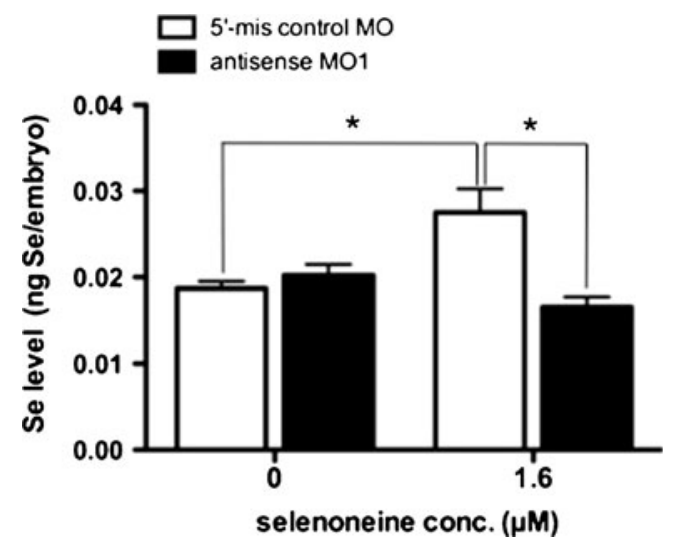

Fig. 2 OCTN1-deficient zebrafish embryos microinjected with antisense morpholino oligo. Total selenium levels of embryos microinjected with 5mis control MO and antisense MO1 in the presence and absence of selenoneine are compared. Asterisk indicates significant difference (ANOVA; $P<0.05$ ) based method for testing $\mathrm{MeHg}$ toxicity. We assayed $\mathrm{MeHg}$ accumulation by measuring total $\mathrm{Hg}$ and Se contents in each embryo and observed morphological defects during embryogenesis in response to MeHgCys at 0-100 ng $\mathrm{Hg} / \mathrm{mL}$ in the culture medium (Fig. 3). Abnormal morphogenesis occurred in a dose-dependent manner following treatment with $\mathrm{MeHgCys}$ at 25-100 ng $\mathrm{Hg} / \mathrm{mL}$. Following treatment with $100 \mathrm{ng} \mathrm{Hg} / \mathrm{mL}$, zebrafish embryos showed disruptions in the formation of the eyes, heart cavity, and larval fin at $48 \mathrm{hpf}$, and TUNEL-positive apoptotic cells were observed (Fig. 3d). We determined the frequency of defects in the eyes, heart cavity, and larval fin (Fig. S4).

When exposed to only MeHgCys, the embryos accumulated $\mathrm{MeHg}$ in a dose-dependent manner (Fig. 4). In the absence of selenoneine, $\mathrm{Hg}$ levels reached $2.7 \mathrm{ng}$ per embryo following treatment with $\mathrm{MeHgCys}$ at $100 \mathrm{ng} \mathrm{Hg} / \mathrm{mL}$, and intracellular Se levels were reduced to $56 \%$ of the level observed in normal control embryos. However, in the presence of $1.6 \mu \mathrm{M}$ selenoneine, $\mathrm{Hg}$ accumulation was decreased to $37 \%$ of the level observed in embryos treated with $\mathrm{MeHgCys}$ only, and normal levels of Se were recovered (Fig. 4). In addition, inorganic $\mathrm{Hg}$ contributed $61 \%$ of the total $\mathrm{Hg}$ content. Total Se levels in embryo brains and blood cells decreased in a dosedependent manner after exposure to MeHgCys (Fig. S5A), and ROS were produced in MeHg-treated embryos (Fig. S5B).

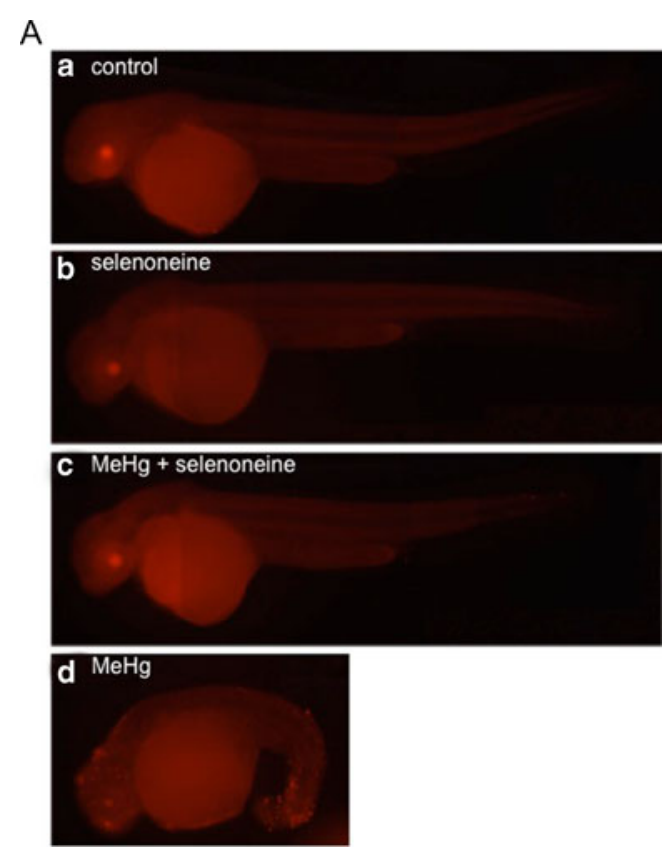

Fig. 3 Protective effect of selenoneine against $\mathrm{MeHg}$ accumulation in zebrafish embryos. Detection of apoptotic cells by whole-mount TUNEL staining in 2-day-old embryos after MeHgCys exposure. No apparent morphological defect was found in the control embryo (a), the embryo treated with only selenoneine (b), or the embryo treated with both MeHgCys and selenoneine (c). Embryos treated with only $\mathrm{MeHgCys}$ showed defects in the eyes, heart cavity, and larval fin, and apoptotic cells (d) 
a selenium

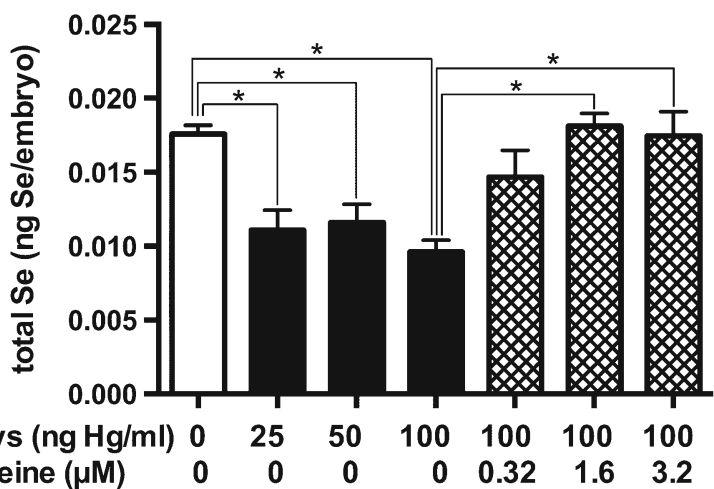

b mercury

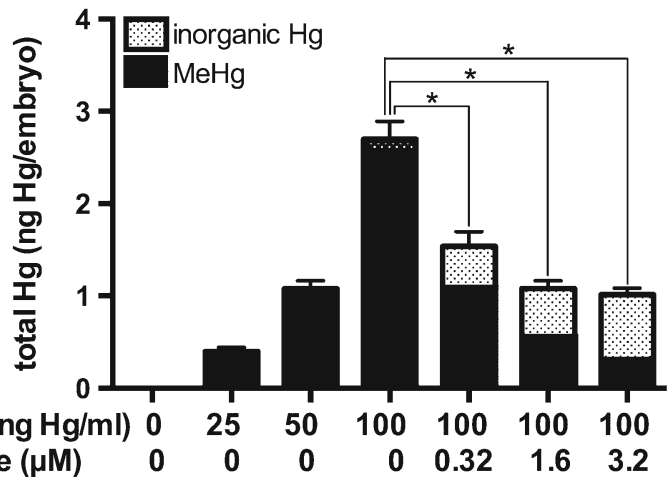

$\begin{array}{lrrrrrrr}\text { MeHgCys (ng Hg/ml) } & 0 & 25 & 50 & 100 & 100 & 100 & 100 \\ \text { selenoneine }(\mu \mathrm{M}) & 0 & 0 & 0 & 0 & 0.32 & 1.6 & 3.2\end{array}$

Fig. 4 The selenium (a) and mercury (b) levels were measured in embryos after exposure to $\mathrm{MeHgCys}$ at $0-100 \mathrm{ng} \mathrm{Hg} / \mathrm{mL}$ for 3 days in the presence and absence of selenoneine. The $\mathrm{MeHg}$, inorganic mercury, and selenium levels were determined in cellular extracts. Values are means $\pm \mathrm{SE}$ of eight individuals. Asterisks denote significant differences (ANOVA; $P<0.05$ )

ROS level in embryos decreased at $100 \mathrm{ng} \mathrm{Hg} / \mathrm{mL}$ compared with those at 25 and $50 \mathrm{ng} \mathrm{Hg} / \mathrm{mL}$, suggesting that oxygen consumption and ROS generation might decrease under severe oxidative stress condition at $100 \mathrm{ng} \mathrm{Hg} / \mathrm{mL}$ of $\mathrm{MeHg}$.

We compared $\mathrm{MeHg}$ accumulation in embryos treated with selenoneine versus ergothioneine, a sulfur analog of selenoneine. Treatment of embryos that had accumulated $\mathrm{MeHg}$ with 0.8 or $1.6 \mu \mathrm{M}$ ergothioneine did not reduce $\mathrm{Hg}$ levels (Fig. S6), indicating that $\mathrm{MeHg}$ accumulation is reduced only by selenoneine, and not by ergothioneine.

\section{Essential Role of OCTN1 in MeHg Detoxification}

in Zebrafish Embryos and Human Cells

We used the zebrafish model to investigate the mechanism by which selenoneine detoxifies MeHg. To examine the relationship between OCTN1 function and $\mathrm{MeHg}$ accumulation in vivo, we measured the MeHg levels in zebrafish embryos that had been injected with an antisense MO and exposed to a low concentration of MeHgCys (10 ng Hg/mL; Fig. 5). After $\mathrm{MeHg}$ exposure, selenium levels in control embryos (5'-mis control MO1 and control MO) were reduced. In contrast, $\mathrm{Hg}$ was accumulated in OCTN1-deficient embryos (antisense MO1 and antisense MO2), and selenium levels were not reduced following $\mathrm{MeHg}$ exposure (Fig. 5).

To confirm the finding that OCTN1-deficiency is associated with $\mathrm{MeHg}$ accumulation, we exposed zebrafish embryos to higher $\mathrm{MeHgCys}$ concentrations. Concentrations greater than $500 \mathrm{ng} \mathrm{Hg} / \mathrm{mL}$ were lethal within $72 \mathrm{hpf}$, and abnormal morphogenesis was observed at 24 hpf (Fig. 6, Fig. S7). When control (5'-mis antisense MO1-injected) embryos were exposed to $\mathrm{MeHgCys}$ at $500 \mathrm{ng} \mathrm{Hg} / \mathrm{mL}$, the embryos died within 3 days (Fig. 6a); however, in the presence of $1.6 \mu \mathrm{M}$ selenoneine, most embryos survived and produced inorganic $\mathrm{Hg}$ (Fig. 6b). Exposure to $\mathrm{MeHgCys}$ at $500 \mathrm{ng} \mathrm{Hg} / \mathrm{mL}$ was always lethal to OCTN1-deficient embryos (Fig. 6a), which accumulated MeHg and died regardless of the presence of selenoneine (Fig. 6b). Nevertheless, with the addition of more selenoneine, survival increased from 54 to $87 \%$ at day 1 and from 32 to $66 \%$ at day 2 (Log-rank Mantel-Cox test; $P<0.0005$ ), the Hg level decreased from 14.6 to $9.6 \mathrm{ng} / \mathrm{embryo}$ (Fig. 6b), and the morphological impact was reduced (Fig. S7).
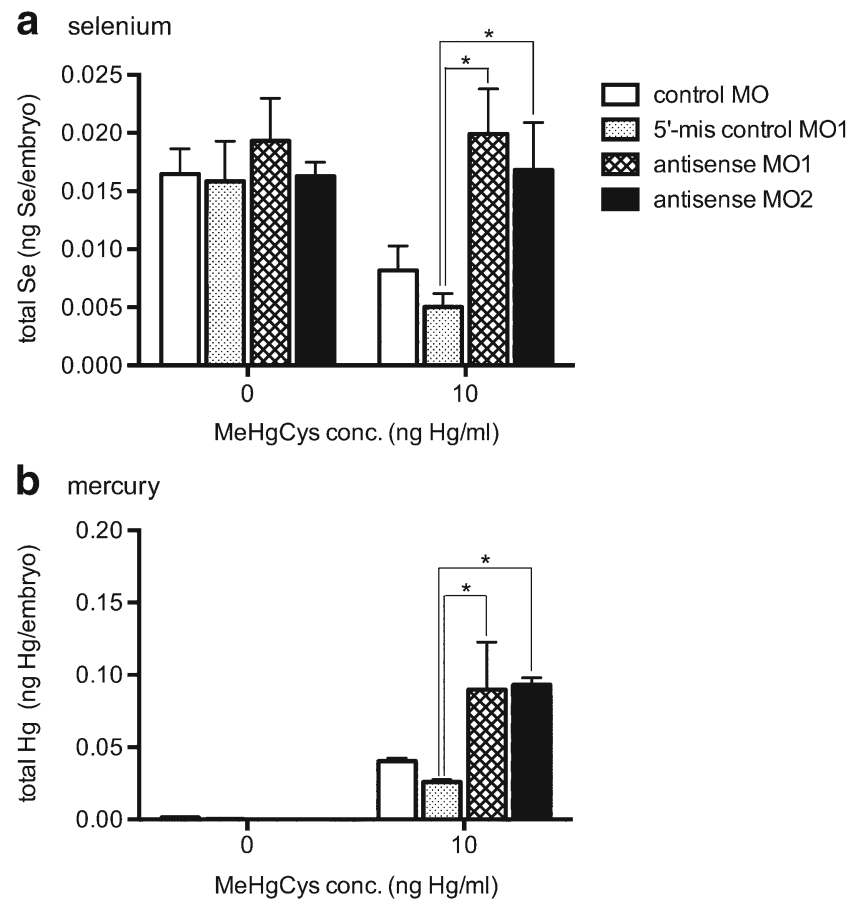

Fig. 5 Accumulation of mercury and selenium in zebrafish embryos after exposure to low concentrations of $\mathrm{MeHg}$. After exposure to MeHgCys at $10 \mathrm{ng} \mathrm{Hg} / \mathrm{mL}$ from 12 to $72 \mathrm{hpf}$, total selenium (a) and mercury (b) levels were determined in control embryos (5'-mis control MO1 and control MO) and in OCTN1-deficient embryos (antisense $\mathrm{MO} 1$ and antisense MO2). Values are means $\pm \mathrm{SE}$ of six individuals. Asterisks indicate significant differences compared with 5'-mis control MO1 embryos (ANOVA; $P<0.05$ ) 

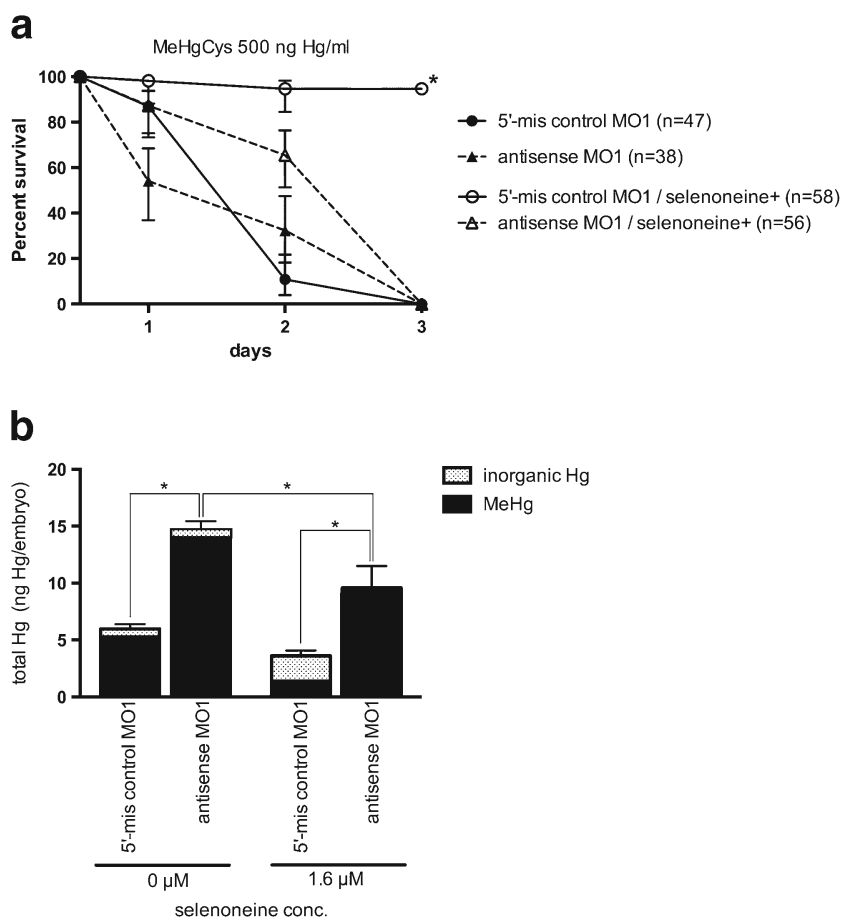

Fig. 6 Protective effect of selenoneine against lethal $\mathrm{MeHg}$ exposure. Zebrafish embryos were exposed to MeHgCys at $500 \mathrm{ng} \mathrm{Hg} / \mathrm{mL}$ in Hank's medium from 12 to $72 \mathrm{hpf}$, and the survival ratios were determined daily. a Survival ratios of antisense MO1-injected embryos and 5'-mis MO1-injected control embryos in the presence of $\mathrm{MeHg}$ $(500 \mathrm{ng} \mathrm{Hg} / \mathrm{mL})$ and 0 or $1.6 \mu \mathrm{M}$ selenoneine. Values are means $\pm \mathrm{SE}$ $(n=38-58)$. Asterisks indicate significant differences between $5^{\prime}$-mis control MO1 and antisense MO1 embryos (Log-rank Mantel-Cox test; $P<0.0001)$. b Mercury levels in control embryos (5-mis control MO1) and OCTN1-deficient embryos (antisense MO1) at $24 \mathrm{hpf}$. Values are means \pm SE of six individuals. Asterisks indicate significant differences between 5'mis control MO1 and antisense MO1 embryos (ANOVA; $P<0.05$ )

To validate these data in human cells, HEK293 cells overexpressing human OCTN1 were exposed to $\mathrm{MeHgCys}$ in the absence and presence of selenoneine. In the absence of selenoneine, $\mathrm{MeHg}$ was accumulated in a dose-dependent manner in the OCTN1-overexpressing cells and the control empty vector-transfected cells (Fig. 7). Intracellular Se levels were reduced after exposure to $\mathrm{MeHg}$ at 25-100 ng $\mathrm{Hg} / \mathrm{mL}$. In the presence of selenoneine, the dose-dependent accumulation of $\mathrm{MeHg}$ was decreased. Furthermore, inorganic $\mathrm{Hg}$ was formed in OCTN1-overexpressing cells, but not in the control empty vector-transfected cells (Fig. 7).

\section{MeHg Detoxification by a Secretory Lysosomal Pathway}

To further characterize $\mathrm{MeHg}$ detoxification mechanisms, we examined $\mathrm{Hg}$ accumulation following $\mathrm{MeHgCys}$ microinjection into the yolk. In control embryos, the intracellular $\mathrm{Hg}$ level decreased to $0.7 \mathrm{ng} / \mathrm{embryo}$ following microinjection of $\mathrm{MeHgCys}(3 \mathrm{ng} \mathrm{Hg}$ ), and inorganic $\mathrm{Hg}$ was produced (1.1 ng/embryo; Fig. 8), indicating that most of the $\mathrm{MeHg}$ introduced into the embryos was excreted. In contrast, the $\mathrm{Hg}$ level increased to $2.2 \mathrm{ng} / \mathrm{embryo}$ in OCTN1-deficient embryos, and little inorganic $\mathrm{Hg}(0.1 \mathrm{ng} / \mathrm{embryo})$ was produced (Fig. 8). Inhibition of the vacuolar-type $\mathrm{H}^{+}$-ATPase in lysosomes by baf enhanced $\mathrm{MeHg}$ accumulation by inhibiting the excretion of $\mathrm{MeHg}$ in the yolk.

To confirm the MeHg excretion mechanism, we collected exosomes from spent embryo culture medium and measured their $\mathrm{Hg}$ content and exosomal marker enzyme activity. Exosomes from the medium of MeHgCys-injected embryos contained higher levels of $\mathrm{Hg}$ than those from OCTN1deficient embryo medium (Fig. 9). In addition, exosomes from OCTN1-overexpressing embryos contained markedly higher levels of $\mathrm{Hg}$ (Fig. 9a). Exosomes with high levels of $\mathrm{Hg}$ also exhibited increased activity of the lysosomal marker enzyme cathepsin L (Fig. 9b).

\section{DISCUSSION}

In the present study, selenoneine reduced $\mathrm{MeHg}$ accumulation and toxicity in HEK293 cells and in a zebrafish embryo toxicity model. Selenoneine was identified as a high-affinity specific physiological ligand for OCTN1, with $K_{\mathrm{m}}$ values of 13.0 and $9.5 \mu \mathrm{M}$ in HEK293 cells and zebrafish blood cells, respectively; previously, human OCTN1 was thought to specifically bind ergothioneine ( $K_{\mathrm{m}}$ of $21 \mu \mathrm{M}$ in HEK293 cells). Moreover, selenoneine was incorporated into human cells and zebrafish blood cells and embryos within $30 \mathrm{~min}$. These findings show that OCTN1 regulates selenoneine absorption and Se metabolism in animal tissues. Given that selenoneine has strong radical scavenging activity (Yamashita and Yamashita 2010; Yamashita et al. 2010, 2011), the distribution and expression of OCTN1 may be responsible for maintenance of the Se redox status. In addition to cation absorption, mammalian OCTN1 is thought to be involved in the secretion of cations in renal proximal tubules and the small intestine (Kato et al. 2010). The present study showed that OCTN1 mediated the excretion of $\mathrm{MeHg}$ in human cells and zebrafish embryos, indicating a role in $\mathrm{MeHg}$ detoxification.

Selenoneine exists as two tautomers, the selenol- and selenoxo-form monomers, and an oxidized dimer (Yamashita and Yamashita 2010). For practical reasons, we used the stable oxidized dimer in the present study. When selenoneine was added to HEK293 culture medium, cell growth was enhanced and ROS levels were reduced (Yamashita et al. 2010). This suggests that the selenoneine oxidized dimer may be reduced by GSH, thus existing intracellularly as a reduced monomer and acting as a scavenger of radicals. OCTN1 and blood ergothioneine have been implicated in the etiology of Crohn's disease (Koepsell et al. 2007; Koh et al. 2002). Therefore, selenoneine redox status, mediated by OCTN1, may be important in Crohn's disease and other inflammatory 
Fig. 7 Protective effects of selenoneine against $\mathrm{MeHg}$ accumulation in HEK293 cells. The cells transiently transfected with human OCTN1 cDNA or mock vector were treated with $\mathrm{MeHgCys}$ at $100 \mathrm{ng} \mathrm{Hg} / \mathrm{mL}$ for $2 \mathrm{~h}$ in the presence and absence of selenoneine. The levels of a inorganic mercury and $\mathrm{MeHg}$ and $\mathbf{b}$ selenium were measured in cell extracts. Values and bars indicate means $\pm \mathrm{SE}$ of three independent experiments. Asterisks denote significant differences between mock control and OCTN1-transfected cells (ANOVA, $P<0.05$ )

\section{a selenium}

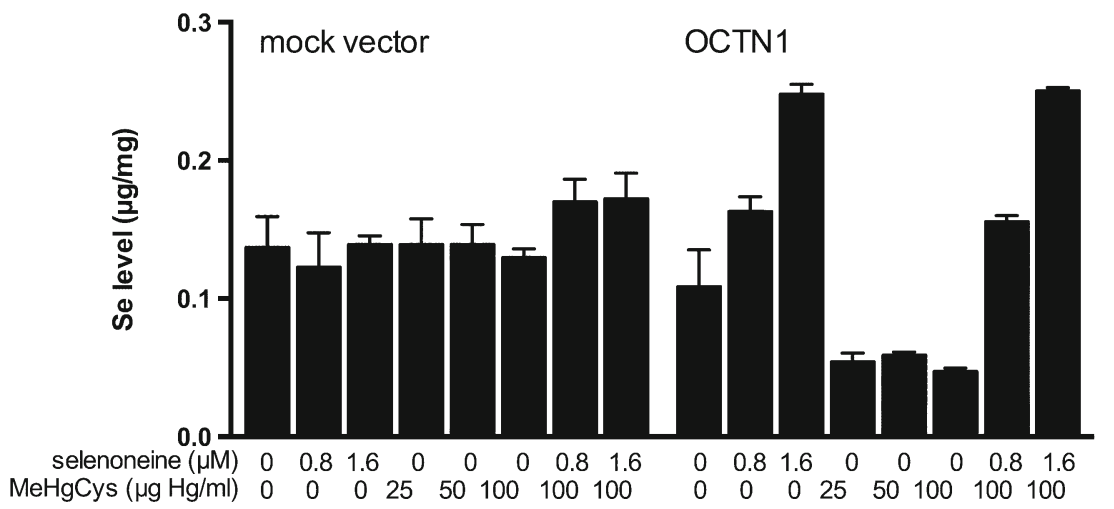

b mercury

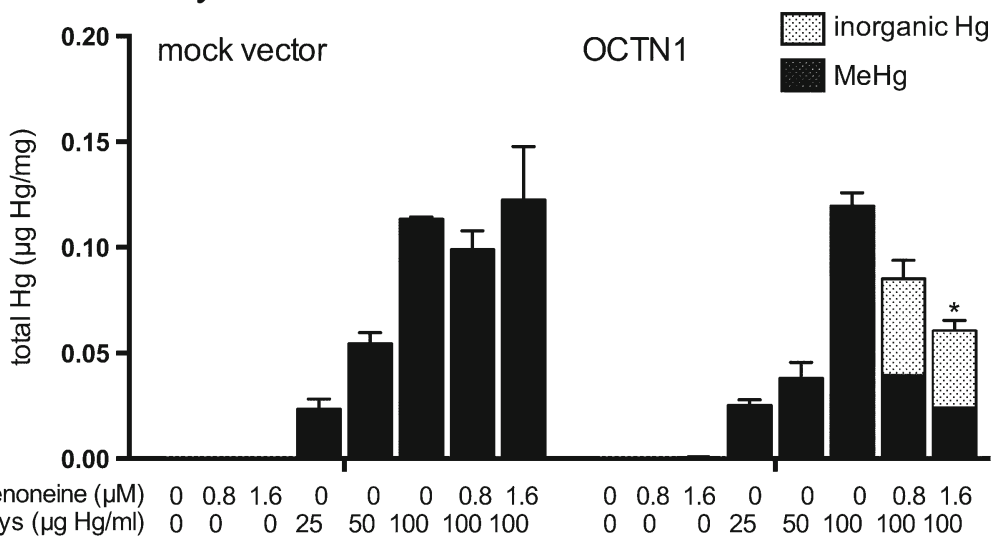

and chronic diseases caused by Se deficiency and/or oxidative damage.
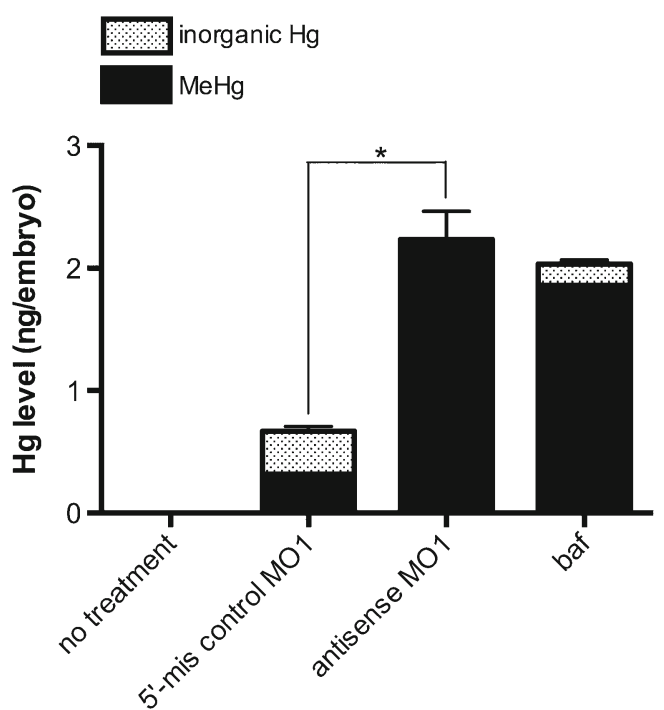

Fig. 8 Excretion of $\mathrm{MeHg}$ by the exosomal secretion pathway. The yolk sacs of embryos were microinjected with $\mathrm{MeHgCys}(3 \mathrm{ng} \mathrm{Hg} /$ individual embryo), and the mercury levels were measured. Values are means $\pm \mathrm{SE}$ $(n=6)$. Asterisks indicate significant differences (ANOVA; $P<0.05$ )
MeHg exposure was lethal to OCTN1-deficient embryos, which accumulated $\mathrm{MeHg}$ and died regardless of the presence of selenoneine. However, with the addition of more selenoneine, the survival of OCTN1-deficient embryos was increased, the level of $\mathrm{Hg}$ decreased, and the morphological impact of $\mathrm{MeHgCys}$ was much reduced. This suggests that in addition to OCTN1, other transporters may be involved in MeHg excretion; these transporters could belong to the solute carrier protein family (Koepsell et al. 2007; Maher et al. 2005) or the ATPbinding cassette $(\mathrm{ABC})$ transporter $\mathrm{ABC}-\mathrm{B}$ and $\mathrm{ABC}-\mathrm{C}$ superfamily (Kato et al. 2010; Kruh and Belinsky 2003; Madejczyk et al. 2007; Maher et al. 2005; Paulusma et al. 1996; Taubert et al. 2005).

In the present study, detoxification of $\mathrm{MeHg}$ was mediated by the OCTN1. Upon exposure to MeHgCys, the Se level decreased in normal control embryos compared with OCTN1deficient embryos, suggesting transport by OCTN1. The Hg level in control embryos was also lower than that in OCTN1deficient embryos. In addition, the presence of exosomes with high levels of $\mathrm{Hg}$ and increased lysosomal cathepsin L activity suggests that exosome production is induced by $\mathrm{MeHg}$ exposure. Furthermore, baf inhibited $\mathrm{MeHg}$ excretion and enhanced its accumulation. These findings indicate that $\mathrm{MeHg}$ was excreted by the secretory lysosomal pathway through 
a mercury levels in the exosomal fraction
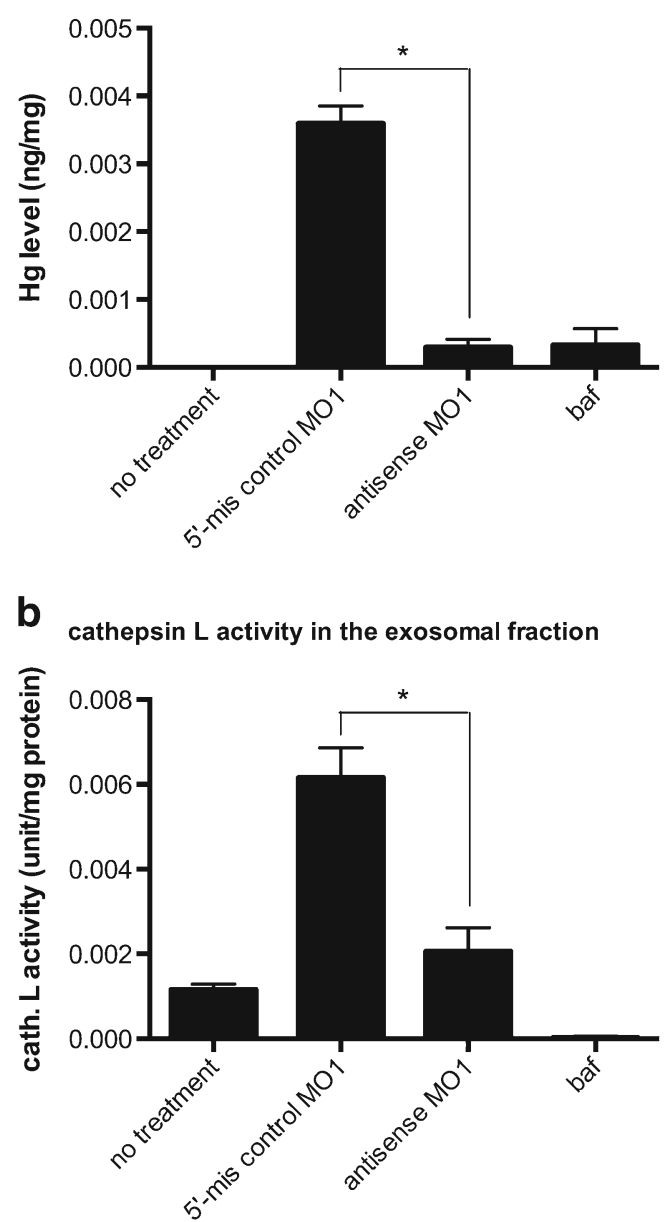

Fig. 9 Total mercury content and cathepsin L activity in the exosomal fraction following $\mathrm{MeHg}$ exposure. Secreted exosomes were collected from the culture medium by ultracentrifugation at $100,000 \times \mathrm{g}$ for $1 \mathrm{~h}$. a Total mercury content in the exosomal fraction. b Activity levels of the lysosomal marker enzyme cathepsin $\mathrm{L}$ in the exosomal fraction. To inhibit lysosomal ATPase function, $5 \mathrm{nM}$ baf was added to the culture medium at $12 \mathrm{hpf}$. Values and bars indicate means $\pm \mathrm{SE}$ of three independent experiments. OCTN1-deficient embryos (antisense MO1) and control embryos (5'-mis control MO1) were compared. Asterisks indicate significant differences (ANOVA; $P<0.05$ )

the function of OCTN1. The yolk was found to possess strong excretion and $\mathrm{MeHg}$ demethylation mechanisms mediated by the selenoneine-OCTN1 system.

Similar phenomena were also observed in OCTN1transfected HEK293 cells, which showed decreased Se levels after MeHgCys treatment compared with the levels in mock vector-transfected cells, suggesting the transport of Se by OCTN1. Hg accumulation was decreased following selenoneine exposure in OCTN1-transfected cells, but not in mock vectortransfected cells, indicating that selenoneine and OCTN1 regulate $\mathrm{MeHg}$ detoxification in human cells. In OCTN1-transfected HEK293 cells, the Hg content decreased only in the presence of selenoneine. The difference in $\mathrm{MeHg}$ detoxification functions between zebrafish embryos and HEK293 cells may be attributable to different levels of endogenous OCTN1 expression and accumulated selenoneine. Zebrafish embryos expressed OCTN1 (Figs. S1 and S2), whereas HEK293 cells expressed OCTN1 only slightly (Fig. S1).

$\mathrm{MeHg}$ accumulation was inhibited in the presence of selenoneine in zebrafish embryo culture. This study clearly showed that OCTN1-deficient embryos microinjected with $\mathrm{MeHgCys}$ contained higher Hg levels than normal control embryos. Thus, we hypothesize that selenoneine-mediated $\mathrm{MeHg}$ excretion as a substrate of the OCTN1 transporter. Therefore, the protective mechanism may involve direct conjugation of selenoneine with $\mathrm{MeHg}$. The selenoneine- $\mathrm{MeHg}$ complex might be formed under reducing conditions in vivo and translocated into the lysosomal secretory vesicles by OCTN1. Following this line of thought, the MeHg complex may be decomposed to inorganic $\mathrm{Hg}$, i.e., mercury selenide ( $\mathrm{HgSe})$. HgSe found in the liver of marine mammals (Friberg and Mottet 1989; Itano et al. 1985; $\mathrm{Ng}$ et al. 2001; Nigro and Leonzio 1996; Palmisano et al. 1995; Skerfving 1978) may be produced from the selenoneine- $\mathrm{MeHg}$ complex by this OCTN1-mediated secretory lysosomal mechanism. In this study, however, no selenoneine-MeHg was detected in MeHg-exposed zebrafish embryos by LC-ICP-MS analysis. We speculate that the selenoneine-MeHg complex may be biologically unstable

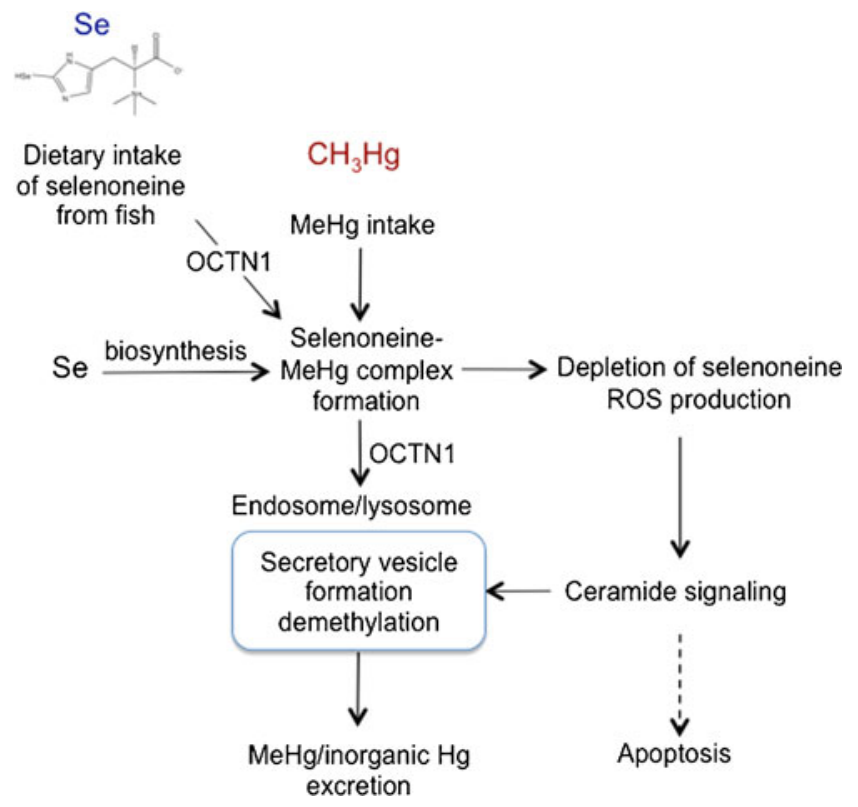

Fig. 10 Hypothesis for the influence of dietary intake of selenoneine on $\mathrm{MeHg}$ accumulation and toxicity. The main dietary source of selenoneine is fish, and it can be biologically synthesized from other selenium sources. Selenoneine plays an important role in selenium redox mechanisms. During $\mathrm{MeHg}$ exposure, selenoneine mediates the uptake of $\mathrm{MeHg}$ into endosomal and/or lysosomal secretion vesicles through OCTN1 function. $\mathrm{MeHg}$ exposure induces oxidative stress owing to the depletion of selenoneine and production of ROS. Stressactivated signaling mechanisms enhance proapoptotic ceramide signals, accelerating $\mathrm{MeHg}$ excretion. Demethylation occurs in the secretory lysosomal vesicles 
and readily decomposed in secretory lysosomal vesicles. In dolphin liver, the demethylation/accumulation of mercury probably involves the formation of $\mathrm{HgSe}$ and selenocompounds from Se-containing residues of specific proteins (Ng et al. 2001). In addition, the molar ratio of $\mathrm{Se}$ and inorganic $\mathrm{Hg}$ was very close to 1 , suggesting that $\mathrm{HgSe}$ may be the end product of $\mathrm{MeHg}$ detoxification. Therefore, the MeHg detoxification mechanism in which selenoneine- $\mathrm{MeHg}$ complexes could be converted to HgSe by OCTN1 function may be commonly distributed in fish and mammals.

Because inorganic Se and selenomethionine supplementation can reduce MeHg toxicity (Friedman et al. 1978; Ganther et al. 1972; Ganther and Sunde 1974), selenoneine may be biologically synthesized from inorganic and/or organic Se in vivo and affect $\mathrm{MeHg}$ protection mechanisms. Our unpublished results using the OCTN1-deficient zebrafish embryos also show that OCTN1 mediates MeHg excretion in the presence of sodium selenite, suggesting that selenoneine produced from selenite may be used for MeHg detoxification (data not shown). Further studies should be undertaken to identify the roles of selenoneine in the Se metabolic pathway.

Recent studies on molecular excretion mechanisms have suggested that exosome vesicles are produced through stimulation by ceramide under oxidative stress conditions (Hannun 1996; Mathias et al. 1993; Okazaki et al. 1989; Verheij et al. 1996; Yabu et al. 2008). Thus, MeHg exposure may induce an oxidative stress response and formation of exosome vesicles containing $\mathrm{MeHg}$ and inorganic $\mathrm{Hg}$. Exosome fractions containing mercury also showed lysosomal cathepsin L activity, implicating the endosomal and/or lysosomal secretion pathways (Nomura and Katsunuma 2005; Blott and Griffiths 2002). Ceramide generation by neutral sphingomyelinase triggers the formation and release of exosomes, and the ESCRT machinery is thought to play important roles in cell-cell communication, antigen presentation, and pathogenesis (Graner et al. 2009; Trajkovic et al. 2008). Thus, exosomal secretion mechanisms are also essential for MeHg detoxification. Under stress conditions, ceramide is produced by the hydrolytic action of sphingomyelinase on sphingomyelin, and c-jun kinase/stressactivated protein kinase pathways are linked to ceramideinduced cell death mechanisms (Hannun 1996; Mathias et al. 1993; Okazaki et al. 1989; Verheij et al. 1996; Yabu et al. 2008). Zebrafish embryos exhibited typical stress-inducible apoptotic features upon MeHg exposure. The detoxification of toxic chemicals and oxidants mediated by selenoneine appears to be a novel exosomal function in animal cells and tissues.

Taken together, these present findings support the hypothesis that $\mathrm{MeHg}$ excretion is mediated by selenoneine and a specific OCTN1, as proposed in Fig. 10. The depletion of selenoneine and production of ROS after $\mathrm{MeHg}$ exposure may trigger ceramide generation and exosome formation. Although a $\mathrm{MeHg}$ demethylation enzyme, similar to bacterial organomercury lyases (Begley et al. 1986), could be present in the $\mathrm{MeHg}$ secretion pathway, $\mathrm{MeHg}$ can be converted to inorganic $\mathrm{Hg}$ directly and non-enzymatically in the presence of Se (Iwata et al. 1982). Further study is required to identify the demethylation reaction and lysosomal vesicle formation mechanism.

In conclusion, we present a mechanism for selenoneine $\mathrm{MeHg}$ excretion and demethylation in human and fish cells. Selenoneine is an essential molecule in this detoxification pathway, and selenoneine and inorganic Hg levels may be useful biomarkers for $\mathrm{MeHg}$ detoxification in animal cells and tissues.

Acknowledgments This work was supported in part by grants from the Ministry of Agriculture, Forestry and Fisheries of Japan.

Open Access This article is distributed under the terms of the Creative Commons Attribution License which permits any use, distribution, and reproduction in any medium, provided the original author(s) and the source are credited.

\section{References}

Auslander M, Yudkovski Y, Chalifa-Caspi V, Herut B, Ophir R, Reinhardt R, Neumann PM, Tom M (2008) Pollution-affected fish hepatic transcriptome and its expression patterns on exposure to cadmium. Mar Biotechnol 10:250-261

Begley TP, Walts AE, Walsh CT (1986) Bacterial organomercurial lyase: overproduction, isolation, and characterization. Biochemistry 25:7186-7192

Blott EJ, Griffiths GM (2002) Secretory lysosomes. Nature Rev Mol Cell Biol 3:122-131

Clarkson TW (1972) Recent advances in toxicology of mercury with emphasis on the alkyl mercurials. Crit Rev Toxicol 1:203-234

Cordeiro OD, Silva TS, Alves RN, Costas B, Wulff T, Richard N, de Vareilles M, Conceição LE, Rodrigues PM (2012) Changes in liver proteome expression of Senegalese sole (Solea senegalensis) in response to repeated handling stress. Mar Biotechnol 14:714-729

De J, Ramaiah N, Vardanyan L (2008) Detoxification of toxic heavy metals by marine bacteria highly resistant to mercury. Mar Biotechnol 10:471-477

Friberg L, Mottet NK (1989) Accumulation of methylmercury and inorganic mercury in the brain. Biol Trace Elem Res 21:201-206

Friedman MA, Eaton LR, Carter WH (1978) Protective effects of freeze dried swordfish on methylmercury chloride toxicity in rats. Bull Environ Cont Toxicol 19:436-443

Ganther HE, Sunde ML (1974) Effect of tuna fish and selenium on the toxicity of methylmercury. J Food Sci 39:1-5

Ganther H, Goudie C, Sunde M, Kopeckey M, Wagner S, Hoekstra W (1972) Selenium: relation to decreased toxicity of methylmercury added to diets containing tuna. Science 175:1122-1124

Gonzalez P, Dominique Y, Massabuau JC, Boudou A, Bourdineaud JP (2005) Comparative effects of dietary methylmercury on gene expression in liver, skeletal muscle, and brain of the zebrafish (Danio rerio). Environ Sci Technol 39(11):3972-3980

Graner MW, Alzate O, Dechkovskaia AM, Keene JD, Sampson JH, Mitchell DA, Bigner DD (2009) Proteomic and immunologic analyses of brain tumor exosomes. FASEB $\mathrm{J}$ 23:1541-1557

Gründemann D, Harlfinger S, Golz S, Geerts A, Lazar A, Berkel R, Jung N, Rubbert A, Schömig E (2005) Discovery of the 
ergothioneine transporter. Proc Natl Acad Sci U S A 102:52565261

Hannun YA (1996) Functions of ceramide in coordinating cellular responses to stress. Science 274:1855-1859

Itano K, Kawai S, Tatsukawa R (1985) Properties of mercury and selenium in salt-insoluble fraction of muscles in striped dolphin. Bull Jpn Soc Sci Fish 51:1129-1131

Iwata H, Masukawa T, Kito H, Hayashi M (1982) Degradation of methylmercury by selenium. Life Sci 31:859-866

Kato Y, Kubo Y, Iwata D, Kato S, Sudo T, Sugiura T, Kagaya T, Wakayama T, Hirayama A, Sugimoto M, Sugihara K, Kaneko S, Soga T, Asano M, Tomita M, Matsui T, Wada M, Tsuji A (2010) Gene knockout and metabolome analysis of carnitine/ organic cation transporter OCTN1. Pharm Res 27:832-840

Koepsell H, Lips K, Volk C (2007) Polyspecific organic cation transporters: structure, function, physiological roles, and biopharmaceutical implications. Pharm Res 24:1227-1250

Koh AS, Simmons-Willis TA, Pritchard JB, Grassl SM, Ballatori N (2002) Identification of a mechanism by which the methylmercury antidotes $N$-acetylcysteine and dimercaptopropanesulfonate enhance urinary metal excretion: transport by the renal organic anion transporter-1, Oat1. Mol Pharmacol 62:921-926

Korbas M, Blechinger SR, Krone PH, Pickering IJ, George GN (2008) Localizing organomercury uptake and accumulation in zebrafish larvae at the tissue and cellular level. Proc Natl Acad Sci U S A 105:12108-12112

Kruh GD, Belinsky MG (2003) The MRP family of drug efflux pumps. Oncogene 22:7537-7552

Kusik BW, Carvan MJ 3rd, Udvadia AJ (2008) Detection of mercury in aquatic environments using EPRE reporter zebrafish. Mar Biotechnol 10:750-757

Ma YB, Zhang ZF, Shao MY, Kang KH, Shi XL, Dong YP, Li JL (2012) Response of sulfide:quinone oxidoreductase to sulfide exposure in the echiuran worm Urechis unicinctus. Mar Biotechnol 14:245-251

Madejczyk MS, Aremu DA, Simmons-Willis TA, Clarkson TW, Ballatori N (2007) Accelerated urinary excretion of methylmercury following administration of its antidote $\mathrm{N}$-acetylcysteine requires mrp2/abcc2, the apical multidrug resistance-associated protein. J Pharm Exp Therap 322:378-384

Maher JM, Slitt AL, Cherrington NJ, Cheng X, Klaassen CD (2005) Tissue distribution and hepatic and renal ontogeny of the multidrug resistance-associated protein (Mrp) family in mice. Drug Metab Dispos 33:947-955

Mathias S, Younes A, Kan CC, Orlow I, Joseph C, Kolesnick RN (1993) Activation of the sphingomyelin signaling pathway in intact EL4 cells and in a cell-free system by IL-1 beta. Science 259:519-522

Ministry of the Environment (2004) Mercury Analysis Manual, Japan

Ng P-S, Ji H, Matsumoto K, Yamazaki S, Kogure T, Takagi T, Nagasawa H (2001) Striped dolphin detoxificates mercury as insoluble $\mathrm{Hg}(\mathrm{S}, \mathrm{Se})$ in the liver. Proc Japan Acad 77:178-183

Nigro M, Leonzio C (1996) Intracellular storage of mercury and selenium in different marine vertebrates. Mar Ecol Prog Ser 135:137-143

Nilsson R, Schultz IJ, Pierce EL, Soltis KA, Naranuntarat A, Ward DM, Baughman JM, Paradkar PN, Kingsley PD, Culotta VC, Kaplan J, Palis J, Paw BH, Mootha VK (2009) Discovery of genes essential for heme biosynthesis through large-scale gene expression analysis. Cell Metab 10:119-130

Nomura T, Katsunuma N (2005) Involvement of cathepsins in the invasion, metastasis and proliferation of cancer cells. J Med Invest 52:1-9

Ohi G, Nishigaki S, Seki H, Tamura Y, Maki T, Minowa K, Shimamura Y, Mizoguchi I, Inaba Y, Takizawa Y, Kawanishi Y (1980) The protective potency of marine animal meat against the neurotoxicity of methylmercury: its relationship with the organ distribution of mercury and selenium in the rat. Food Cosmet Toxicol 18:139-145
Okazaki T, Bell RM, Hannun YA (1989) Sphingomyelin turnover induced by vitamin D3 in HL-60 cells. Role in cell differentiation. J Biol Chem 264:19076-19080

Palmisano F, Cardellicchiob N, Zambonin PG (1995) Speciation of mercury in dolphin liver: a two-stage mechanism for the demethylation accumulation process and role of selenium. Mar Environ Res 40:109-121

Paulusma CC, Bosma PJ, Zaman GJ, Bakker CT, Otter M, Scheffer GL, Scheper RJ, Borst P, Oude Elferink RP (1996) Congenital jaundice in rats with a mutation in multidrug resistance-associated protein gene. Science 271:1126-1128

Petroni D, Tsai J, Agrawal K, Mondal D, George W (2012) Low-dose methylmercury-induced oxidative stress, cytotoxicity, and tauhyperphosphorylation in human neuroblastoma (SH-SY5Y) cells. Environ Toxicol 27:549-555

Raymond LJ, Ralston NV (2004) Mercury:selenium interactions and health implications. SMDJ Seychelles Med Dent J 7:5256

Raymond LJ, Seale LA, Ralston NV (2012) Seafood selenium in relation to assessments of methylmercury exposure risks. In: Hatfield DL, Berry MJ, Gladyshev VN (eds) Selenium: its molecular biology and role in human health, Thirdth edn. Springer, New York

Reyes LH, Rahman GMM, Kingston HMS (2009) Robust microwave-assisted extraction protocol for determination of total mercury and methylmercury in fish tissues. Anal Chim Acta 631:121-128

Samson JC, Goodridge R, Olobatuyi F, Weis JS (2001) Delayed effects of embryonic exposure of zebrafish (Danio rerio) to methylmercury $(\mathrm{MeHg})$. Aquat Toxicol 51:369-376

Skerfving S (1978) Interaction between selenium and methylmercury. Environ Health Perspect 25:57-65

Tamai I, Yabuuchi H, Nezu J, Sai Y, Oku A, Shimane M, Tsuji AA (1999) Cloning and characterization of a novel human $\mathrm{pH}$-dependent organic cation transporter, OCTN1. FEBS Lett 419:107-111

Taubert D, Grimberg G, Jung N, Rubbert A, Schömig E (2005) Functional role of the 503F variant of the organic cation transporter OCTN1 in Crohn's disease. Gut 54:1505-1506

Trajkovic K, Hsu C, Chiantia S, Rajendran L, Wenzel D, Wieland F, Schwille P, Brügger B, Simons M (2008) Ceramide triggers budding of exosome vesicles into multivesicular endosomes. Science 319:1244-1247

Usuki F, Yamashita A, Fujimura M (2011) Methylmercury-induced relative selenium deficiency causes oxidative stress through its posttranscriptional effect. J Biol Chem 286:6641-6649

Verheij M, Bose R, Lin XH, Yao B, Jarvis WD, Grant S, Birrer MJ, Szabo E, Zon LI, Kyriakis JM, Haimovitz-Friedman A, Fuks Z, Kolesnick RN (1996) Requirement for ceramideinitiated SAPK/JNK signalling in stress-induced apoptosis. Nature 380:75-79

Weber GJ, Choe SE, Dooley KA, Paffett-Lugassy NN, Zhou Y, Zon LI (2005) Mutant-specific gene programs in the zebrafish. Blood 106:521-530

Weber DN, Connaughton VP, Dellinger JA, Klemer D, Udvadia A, Carvan MJ (2008) Selenomethionine reduces visual deficits due to developmental methylmercury exposures. Physiol Behav 93:250-260

Westerfield M (1995) The zebrafish book. University of Oregon Press, Oregon

Yabu T, Imamura S, Yamashita M, Okazaki T (2008) Identification of $\mathrm{Mg}^{2+}$-dependent neutral sphingomyelinase 1 as a mediator of heat stress-induced ceramide generation and apoptosis. J Biol Chem 283:29971-29982

Yamashita M, Konagaya S (1990) High activities of cathepsins B, D, $\mathrm{H}$, and $\mathrm{L}$ in the white muscle of chum salmon in spawning migration. Comp Biochem Physiol B95:149-152 
Yamashita Y, Yamashita M (2010) Identification of a novel seleniumcontaining compound, selenoneine, as the predominant chemical form of organic selenium in the blood of bluefin tuna. J Biol Chem 285:18134-18138

Yamashita Y, Omura Y, Okazaki E (2005) Total mercury and methylmercury levels in commercially important fishes in Japan. Fish Sci 71:1029-1035

Yamashita M, Mizusawa N, Hojo M, Yabu T (2008) Extensive apoptosis and abnormal morphogenesis in pro-caspase-3 transgenic zebrafish during development. J Exp Biol 211:1874-1881
Yamashita Y, Yabu T, Yamashita M (2010) Discovery of the strong antioxidant selenoneine in tuna and selenium redox metabolism. World J Biol Chem 1:144-150

Yamashita Y, Amlund H, Suzuki T, Hara T, Hossain AM, Yabu T, Touhata K, Yamashita M (2011) Selenoneine, total selenium, and total mercury content in the muscle of fishes. Fish Sci 77:679-686

Yin Z, Milatovic D, Aschner JL, Syversen T, Rocha JB, Souza DO, Sidoryk M, Albrecht J, Aschner M (2007) Methylmercury induces oxidative injury, alterations in permeability and glutamine transport in cultured astrocytes. Brain Res 1131:1-10 